\title{
Digital Civics
}

Pre-publication version of a chapter submitted to Digital Geographies, edited by James Ash, Rob Kitchin and Agnieszka Leszczynski.

Taylor Shelton

Department of Geosciences

Mississippi State University

108 Hilbun Hall

Mississippi State, MS 39762

e-mail: taylor.shelton@msstate.edu 


\section{The Emergence of Digital Civics}

The rapid growth and prevalence of digital technologies in recent decades has often been heralded as an inherently democratizing force, providing citizens with new ways of interacting with one another and organizing towards collective goals. With prominent cases such as the US presidential campaigns of Howard Dean in 2004 and Barack Obama in 2008 and the massive protests of repressive political regimes during the Arab Spring of 2011, examples abound of the increasingly important role played by digital technologies in facilitating citizen participation and political organizing. That being said, there are numerous reasons to doubt that the most important effect of these digital technologies is a trend towards democratization.

Persistent inequalities in access to digital technologies and the skills to use them - whether across race, gender, age, disability, income or geography - mean that significant numbers of people aren't even able to access such tools, much less use them for socially beneficial, altruistic ends. Similarly, it is evident that many of the same technologies heralded for their role in prominent political protest can be just as readily used for the purposes of surveilling and repressing political dissidents. Despite the fact that this popular narrative around democratization is a good bit more complicated than typically assumed, digital technologies are undoubtedly playing an important role in shaping politics and governance across multiple scales, especially with respect to the way citizens are enrolled in such processes and allowed to participate in them.

This chapter reviews some of the key ways that civic engagement and public participation have become increasingly digitized and data-driven. But rather than engaging in debates over the democratic potential of digital technologies, it's arguably more productive to look at the range of ways that this emerging 'digital civics' is reconfiguring how we conceptualize and practice citizenship in the era of big data. The chapter first turns to discussing how citizenship is increasingly defined in relation to data and data practices, and how these redefinitions have precipitated larger changes in the way citizenship is conceptualized and operationalized. Second, the chapter identifies three ongoing, interrelated changes to the digital civics landscape that are worthy of greater attention moving forward. These include the spatialization of digital civics, the corporatization of digital civics, and the growing prominence of oppositional uses of digital civics that seek to challenge the social and political status quo.

\section{The Datafication of Citizenship}

As digital technologies are seen less and less as technologies for communication, they are increasingly viewed as platforms for producing and analyzing massive amounts of data about any number of social processes. Given this shift, scholars have also turned to understanding what this increasing 'datafication' of social life means for different realms. As an outcome of this emerging research agenda into data and society, scholars have identified two key effects of digital technologies on citizenship: first, the performance of citizenship is increasingly oriented around data, and second, this focus on data results in a redefinition of how citizenship is defined and where it is located.

While many of the most prominent examples of digital technologies being incorporated into forms of governance and politics are adopted by large institutions, these technologies are simultaneously directed at citizens and processes of civic participation. This dynamic is highlighted in designer Dan Hill's (2013) call for a shift from 'smart cities' to 'smart citizens', which attempts to valorize the 
more piecemeal, bottom-up and citizen-driven ways that technology is being used to affect change in local communities. Townsend (2014) puts the smartphone at the center of these efforts, arguing that " $[\mathrm{t}]$ hese devices are both a new lens on the dynamic life of the city around us, and the remote controls we can use to activate the world at a distance" (25). While the ability to access information about the city on-the-go, or even provide feedback and additional information to the city itself, can allow for new ways of interacting with each other and our environment, this dynamic has also had broader ramifications for how we actually conceptualize and practice citizenship.

For Jennifer Gabrys (2014), "[m]onitoring and managing data in order to feed back information into urban systems are practices that become constitutive of citizenship. Citizenship transforms into citizen sensing, embodied through practices undertaken in response to (and communication with) computational environments and technologies" (34). That is, the definition and performance of 'good' citizenship is tied to citizens using the technologies in their hands or pockets in order to contribute data back to their city or to the public-at-large. Whether this is through a more active and deliberate contribution like using local 311 issue-reporting applications or even through a more passive participation of allowing one's self to be tracked by sensors embedded in the built environment without raising complaints about privacy, the end result is that " $[\mathrm{t}]$ he citizen is a data point, both a generator of data and a responsive node in a system of feedback" (Gabrys, 2014: 38). Regardless of what particular form this data takes or what issue it seeks to address, it is through being made into data that citizens (and their experiences, opinions and concerns) are made to 'matter' (Wilson, 2011a).

But turning civic participation into a process defined by data doesn't inexorably lead to greater efficiency or responsiveness to citizen concerns. If anything, this process ultimately works to limit the scope of citizen participation, often foreclosing the possibility of proposing or even creating radical alternatives, while channeling action into the much more limited realm of increasing the efficiency of different processes through informational interventions. As Wilson (2011b) describes in the case of a neighborhood indicators project in Seattle, the codification of urban social problems into discrete categories can allow some problems to go unnoticed while surface-level manifestations are treated in isolation from their broader causes. For Wilson, "this move to place these assessment technologies in the hands of residents worked to shift citizens away from complaint systems and into reporting systems" (2011b: 370). That being said, Offenhuber (2015) has shown that not all reporting systems are made equal, with the design of such applications allowing (or at times discouraging) more contentious and critical comments about community issues. So even as citizens are almost uniformly responsibilized through data - shifting the onus for collecting and analyzing data in order to make and enact policy from the state onto citizens - the forms this responsibility takes are decidedly limited.

At the same time as the scope of citizenship is reduced to being, and contributing, data points, so too are the terms of citizenship being reconfigured through this focus on data. Indeed, in many ways it isn't the actual data itself that is most important, but rather how data helps to further reorient social structures and processes. One of the most frequently discussed manifestations of this new digital civics is the civic hackathon, one-off events that bring together teams of citizen technologists to work intensely on a given civic problem for a short period of time. But as a growing body of literature suggests, these events rarely produce meaningful technological outputs, and are instead focused on shaping the broader discourse around certain social problems and providing motivation for continued involvement in technology-centric forms of citizen participation (cf. Di Salvo et al., 2014; Lodato and Di Salvo, 2016; Robinson and Johnson, 2016; Schrock, forthcoming). This 
distinction is important, as Leszczynski (2016) argues that it's necessary to focus not only on the particular forms that data takes in the context of governance practices, but also the ways that data helps to create particular visions of the future. And just as civic apps structure what civic and political participation can look like in the present and future, so too do hackathons, which Schrock (2017) argues tend towards fundamentally "conservative civic visions". That is, the vision of the future offered up by these ostensibly participatory events is a kind of technocratic, instrumental rationality that continues to privilege the role of data in urban governance (Perng and Kitchin, 2016), and, despite the limited track record in producing meaningful products out of such data, focuses on certain kinds of technological and design products that ultimately foreclose critical inquiry into the issues at hand (Gregg, 2015; Lodato and Di Salvo, 2016; Schrock, forthcoming).

This increasingly prominent understanding of citizenship vis-à-vis data has also worked to redefine who is a citizen and how citizenship is defined spatially. In particular, there is a shift away from citizenship as a formal legal status defined through place-based identities. As technical expertise, especially the ability to manipulate data, is increasingly valorized, those who possess this expertise are given a privileged seat at the proverbial table, even when they don't possesses the formal legal status of citizenship (or even residence) in a given place. As Shelton and Lodato (2016) demonstrate in the case of smart cities programs in Atlanta, this privileging of technical expertise leads to an inability on the part of municipal officials to grapple with the specifics of who citizens are and what their needs may be, as citizens without such technical acumen are largely excluded from planning and decision-making processes in favor of experts who make decisions on their behalf. Ultimately, citizenship is defined less by the actual places where one holds the legal status of citizenship and more by the kinds of expertise that one can contribute regardless of place of origin, residence or personal investment in a given locality. At the same time, the spaces where citizenship is presumed to exist are also being reconfigured, privileging hackathons or the digital spaces of apps and open data portals, while material public spaces are being made less accessible to citizens. Citizen protest and participation in these more conventional locations are seen to be disruptive to the social order, rather than constitutive of it, a fact that has been demonstrated by responses to Black Lives Matter and Occupy protests in recent years. But as citizenship has increasingly become defined and reconfigured in relation to the discourses and practices of digital data, so too have these changes beget further shifts in how citizenship and civic participation are being practiced. The following sections attempt to trace three emerging trends within digital civics that are deserving of future attention.

\section{The Spatialization of Digital Civics}

The first emerging trend is the increasing spatialization of digital civics. As civic participation is increasingly mediated by the digital, so too are these digital traces increasingly tied explicitly to geography. This explosion of spatial data has meant a growth in mapping tools and platforms, data dashboards and dynamic visualizations to be used in civic participation processes so as to demonstrate the fundamental connection between space, place and social processes. Whether described as neogeography, volunteered geographic information, or the geoweb, this more spatiallyexplicit manifestation of the broader web 2.0 ethos (Johnson and Sieber, 2012) means that more conventional ways of thinking about and representing geographic processes are becoming more central to the broader civic imaginary. These practices range from attaching locational data to the kinds of issue-reporting application described above, to using simple web maps to raise awareness about a given issue of local importance, or the use of more complex spatial analytical techniques and 
representations to make the case for civic action. At the same time, these new spatial technologies are also working to reshape the way people interact with maps and spatial data, providing something of an inadvertent response to longstanding critiques of mapping as privileging masculinist, imperialist and Cartesian knowledges, instead allowing for a wider range of epistemological and ontological approaches to be realized within digital mapping (Elwood, 2008; Warf and Sui, 2010; Elwood and Leszczynski, 2013).

Though the emergence of these new platforms and forms of data means that spatial information has become more readily accessible and more variegated in form, Haklay (2013) has cautioned against viewing this quantitative growth with a qualitative shift in how these technologies are able to be used by everyday people. So despite the promise of this more spatially-explicit iteration of digital civics of allowing for greater engagement with place-specific issues as originally suggested by Goodchild (2007), these technologies have done little to overcome longstanding barriers that mean that the voices of well-educated, relatively affluent, white men are overrepresented in such platforms. As Haklay argues, "[t] he main error in the core argument of those who promote it as a democratic force is the assumption that, by increasing the number of people who utilise geographic information in different ways and gain access to geographic technology, these users have been empowered and gained more political and social control...neogeography has merely opened up the collection and use of this information to a larger section of the affluent, educated, and powerful part of society" (2013: 66).

\section{The Corporatization of Digital Civics}

This limited potential for a deeper democratization of digital technology has undoubtedly been shaped by the simultaneous corporatization of digital civics. Emerging in conjunction with the spatialization of civic participation, the increased need for technical expertise in order to enact these kinds of digital spatial platforms and processes means that corporate technology vendors are stepping in to facilitate on behalf of, or at least in conjunction with, local governments. But this moment extends beyond what Leszczynski (2012) describes as the neoliberalization of mapping, with the state and other more-or-less public institutions being replaced by private corporations in the provision of spatial information. Now, because of the centrality of spatial data to the practice of datafied citizenship described above, the act of civic engagement itself requires the participation, if not beneficence, of technology corporations.

Key players in the mapping industry, including market-leader Esri and relative newcomers Mapbox and Carto, have all launched some type of municipal government or civic participation program or platform in recent years (Carto, 2015; Poon, 2016; Turner, 2016). While many of these programs seem targeted at providing a combination of software services and technical expertise to city governments in need, the controversial ride-hailing app Uber has taken a different approach with their municipal government outreach. Recognizing that the data collected by the platform is extremely valuable to municipal governments in attempting to understand the everyday mobilities of urban residents, Uber appears to be providing limited access to their proprietary data as a way of extracting concessions from local governments who have previously been keen to regulate such ridehailing apps (Poon, 2017). Even the most visible institution in the ostensibly non-profit wing of the digital civics space, Code for America, has played an active role in spinning off the projects from its fellowship program into for-profit tech startups, with platforms like LocalData and CivicInsight 
emerging out of the Detroit and New Orleans fellowship teams and their work on data platforms for analyzing vacant properties in these respective cities.

For some municipalities invested in becoming 'smarter' and more data-driven, it is only through partnerships with these kinds of corporations that such goals can be realized. Whether through direct procurement or more mutually-beneficial partnership agreements, cities not only require the technology and services provided, but also seek to acquire the reputational capital that comes with such public-private partnerships. For example, in Louisville, Kentucky, the Metro government has not only sought to participate in a variety of technical assistance programs provided through nonprofits like Code for America, Bloomberg Philanthropies, the Rockefeller Foundation and others, but also developed partnerships with for-profit companies like IBM, OpportunitySpace, MySidewalk, Asthmapolis and LocalData. This kind of corporatization of digital civics is, in many ways, a result of the fact that most municipal governments don't have the internal capacity necessary to do the kind of data-intensive work being promoted, especially in an era of fiscal austerity. Instead, they turn to the external institutions where this kind of expertise is increasingly concentrated. But this process ends up in a self-reinforcing cycle, where local capacity and expertise is never built, but instead continually outsourced to private companies (often located in an entirely different city or state) who are able to extract money from local government, while also continuing to privilege technological solutions to intensely social problems.

\section{$\underline{\text { V. Emerging Oppositional Uses of Digital Civics }}$}

But just as digital civics, like so many other areas of social life, has been increasingly colonized by technology corporations and an overarching neoliberal ethos, so too has there been a countermovement to claim the potential for these technologies to act as a means towards more radical and emancipatory ends. Rather than reinforcing corporate power, encouraging the rollback of governmental services and enshrining the value of technical expertise, these emerging oppositional uses of digital civics seek to challenge the social and political status quo. These projects demonstrate that in an era where data is increasingly privileged as the primary means by which citizenship is expressed, data can be just as usefully used by citizens for their own purposes, even serving as the grounds on which broader political claims are made (Taylor et al., 2014; Shelton et al., 2015; Le Dantec et al., 2016). Drawing, if at times implicitly, on a longer history of counter-mapping (cf. Peluso, 1995), these more confrontational and contentious uses of digital data and mapping technologies seek to demonstrate that these tools don't inherently lead to the kinds of problematic understandings of social and spatial processes and naturalization of social inequality and stigma common among more institutional iterations of digital technologies (cf. Shelton, 2017; Jefferson, forthcoming). Instead, they use data analysis and visualization to promote critical, counterhegemonic understandings of, and interventions into, any number of social problems.

Among those issues most frequently targeted by this 'counter data' movement has been the global housing crisis. From the Bay Area's Anti-Eviction Mapping Project ${ }^{1}$ to Detroit's Property Praxis ${ }^{2}$ and the translocal investigations of Inside Airbnb ${ }^{3}$, these more oppositional iterations of digital civics show its potential to challenge, not just reinforce, existing social hierarchies. While each of

\footnotetext{
${ }^{1} \mathrm{http}: / /$ www.antievictionmap.com/

2 http://www.propertypraxis.org/

${ }^{3}$ http://www.insideairbnb.com/
} 
these projects are powerful in part because of the compelling interactive visualizations they've produced, they are also important insofar as they help to break the long-assumed link between mapping and spatial analytical methods with a kind of naïve logical positivism (Wyly, 2009). None of these projects purport to be neutral, simply describing the world as it is through quantitative data. Instead, they all bring a particular political position to bear on the data and resulting analyses, which redirects the conversation about these issues from what might simply appear to be the case, to the underlying levers of technology-based gentrification processes, tax foreclosure and property speculation that are wreaking havoc on residents and housing markets in these places.

Despite being enabled by and articulated through digital technology, these emerging contentious forms of digital civics echo the roots of 'civics' in the pre-digital mapping and urban fieldwork of Patrick Geddes and other early social reformers (Guldi, 2017). Indeed, they also represent a realization of Sieber and Johnson's (2015) more contemporary call for open data to go beyond just the provision of data as an end in itself, and towards open data as a means of furthering agendas of inclusion and participation. So even as many of these projects operate less from the frame of open data or civic technology, and more from the position of using these technologies as a means towards articulating radical alternatives to the status quo, they mobilize many of the same tools and approaches as more institutionally-based forms of digital civics, highlighting the flexibility of these technologies within different social and organizational contexts and the contradictions in how the growing importance of data is reshaping citizenship and civic participation.

\section{$\underline{\text { VI. References }}$}

Carto (2015) "Urban Insights: an Analysis of the Future of Our Cities and Technology". White Paper. Available from: http://go.cartodb.com/hubfs/SmartCitiesWhitePaper.pdf

DiSalvo, Carl, Melissa Gregg, and Thomas Lodato (2014) "Building Belonging." interactions, 21 (4): $58-61$.

Elwood, Sarah (2008) "Volunteered Geographic Information: Future Research Directions Motivated by Critical, Participatory, and Feminist GIS.” GeoJournal, 72 (3-4): 173-183.

Elwood, Sarah, and Agnieszka Leszczynski (2013) "New Spatial Media, New Knowledge Politics." Transactions of the Institute of British Geographers, 38 (4): 544-559.

Gabrys, Jennifer (2014) "Programming Environments: Environmentality and Citizen Sensing in the Smart City." Environment and Planning D: Society and Space, 32 (1): 30-48.

Goodchild, Michael (2007) "Citizens as Sensors: The World of Volunteered Geography." GeoJournal, 69 (4): 211-221.

Gregg, Melissa (2015) "Hack for Good: Speculative Labour, App Development and the Burden of Austerity." The Fibreculture Journal, 25: 183-201.

Guldi, Jo (2017) “A History of the Participatory Map.” Public Culture, 29 (1): 79-112.

Haklay, Muki (2013) "Neogeography and the Delusion of Democratisation." Environment and Planning A, 45 (1): 55-69.

Hill, Dan (2013) “On the Smart City; Or, a 'Manifesto' for Smart Citizens Instead.” Cityofsound. 1 February. Available from: http://www.cityofsound.com/blog/2013/02/on-the-smart-city-acall-for-smart-citizens-instead.html 
Jefferson, Brian Jordan (forthcoming) "Predictable Policing: Predictive Crime Mapping and Geographies of Policing and Race." Annals of the American Association of Geographers.

Johnson, Peter A., and Renee E. Sieber (2012) "Motivations Driving Government Adoption of the Geoweb.” GeoJournal, 77 (5): 667-680.

Le Dantec, Christopher A., Caroline Appleton, Mariam Asad, Robert Rosenberger, and Kari Watkins (2016) "Advocating through Data: Community Visibilities in Crowdsourced Cycling Data.” In A. Golub, M.L. Hoffmann, A.E. Lugo, and G.F. Sandoval (eds.), Bicycle Justice and Urban Transformation: Biking for All?. Routledge. pp. 70-85.

Leszczynski, Agnieszka (2012) "Situating the Geoweb in Political Economy." Progress in Human Geography, 36 (1): 72-89.

Leszczynski, Agnieszka (2016) "Speculative Futures: Cities, Data, and Governance beyond Smart Urbanism.” Environment and Planning A, 48 (9): 1691-1708.

Lodato, Thomas James, and Carl DiSalvo (2016) "Issue-Oriented Hackathons as Material Participation.” New Media \&o Society, 18 (4): 539-557.

Offenhuber, Dietmar (2015) "Infrastructure Legibility—a Comparative Analysis of open311-Based Citizen Feedback Systems.” Cambridge Journal of Regions, Economy and Society, 8 (1): 93-112.

Peluso, Nancy Lee (1995) "Whose Woods Are These? Counter-Mapping Forest Territories in Kalimantan, Indonesia.” Antipode, 27 (4): 383-406.

Perng, Sung-Yueh, and Rob Kitchin (forthcoming) "Solutions and Frictions in Civic Hacking: Collaboratively Designing and Building Wait Time Predictions for an Immigration Office." Social \& Cultural Geography.

Poon, Linda (2016) "Helping Smart Cities Harness Big Data”. CityLab. 29 September. Available from: https://www.citylab.com/life/2016/09/how-mapbox-will-help-smart-cites-tackleurban-challenges/502241/

Poon, Linda (2017) "Finally, Uber Releases Data to Help Cities with Transit Planning". CityLab. 11 January. Available from: https://www.citylab.com/transportation/2017/01/finally-uberreleases-data-to-help-cities-with-transit-planning/512720/

Robinson, Pamela J., and Peter A. Johnson (2016) "Civic Hackathons: New Terrain for Local Government-Citizen Interaction?” Urban Planning, 1 (2): 65-74.

Schrock, Andrew (forthcoming) "'Hackathons With No Hacking': Civic Hackathons and the Performance of Innovation". In C. Watkins (ed.), Rethinking the Innovation Economy: Exploring the Future of Technology, Social Inequality, and Creative Labor. Routledge.

Shelton, Taylor (2017) “The urban geographical imagination in the age of Big Data.” Big Data \& Society, 4 (1): 1-14.

Shelton, Taylor and Thomas Lodato (2016) “"Actually existing smart citizens': expertise and (non)participation in the making of the smart city". Paper presented at Creating the Smart City Workshop, Maynooth University. Maynooth, Ireland. September 5.

Shelton, Taylor, Matthew Zook, and Alan Wiig (2015) "The 'actually existing smart city."' Cambridge Journal of Regions, Economy and Society, 8 (1): 13-25. 
Sieber, Renee E., and Peter A. Johnson (2015) "Civic Open Data at a Crossroads: Dominant Models and Current Challenges." Government Information Quarterly, 32 (3): 308-315.

Taylor, Alex S., Siân Lindley, Tim Regan, and David Sweeney (2014) "Data and Life on the Street." Big Data \& Society, 1 (2): 1-7.

Townsend, Anthony (2014) 'To Know Thy City, Know Thyself”. In D. Hemment and A. Townsend (eds.), Smart Citizens. FutureEverything. pp. 23-26.

Turner, Andrew (2016) "Data-driven citizenship". Esri Insider. 27 September. Available from: https://blogs.esri.com/esri/esri-insider/2016/09/27/data-driven-citizenship/

Warf, Barney, and Daniel Sui (2010) "From GIS to Neogeography: Ontological Implications and Theories of Truth." Annals of GIS, 16 (4): 197-209.

Wilson, Matthew W. (2011a) "Data Matter(s): Legitimacy, Coding, and Qualifications-of-Life." Environment and Planning D: Society and Space, 29 (5): 857-872.

Wilson, Matthew W. (2011b) “"Training the Eye': Formation of the Geocoding Subject.” Social \& Cultural Geography, 12 (4): 357-376.

Wyly, Elvin (2009) “Strategic Positivism.” The Professional Geographer, 61 (3): 310-322. 